\title{
Nitrogen rather than streamflow regulates the growth of riparian
}

\section{trees}

Keyi Wang ${ }^{1}$, Xiaomin Zeng $^{1}$, Xiaohong Liu ${ }^{1 *}, 2$, Matthew Lanning ${ }^{3}$, Guoju Wu ${ }^{2}$, Liangju Zhao ${ }^{4}$, Guobao $\mathrm{Xu}{ }^{2}$, Yabo Wang ${ }^{1}$, Lingnan Zhang ${ }^{1}$, Xiaoqin Li ${ }^{1}$, Qiangqiang Lu ${ }^{1}$, Lixin Wang ${ }^{3}$

1. School of Geography and Tourism, Shaanxi Normal University, Xi'an 710119, China

2. State Key Laboratory of Cryospheric Sciences, Northwest Institute of Eco-Environment and Resources, Chinese Academy of Sciences, Lanzhou 730000, China

3. Department of Earth Sciences, Indiana University-Purdue University Indianapolis (IUPUI), Indianapolis, IN 46202, USA

4. Shaanxi Key Laboratory of Earth Surface System and Environmental Carrying Capacity, College of Urban and Environmental Sciences, Northwest University, Xi'an 710127, China

\section{Running title: Riparian tree ring $\delta^{15} \mathrm{~N}$ in inland river}

* Author for Correspondence: Xiaohong Liu

E-mail:xhliu@snnu.edu.cn; liuxh@lzb.ac.cn

Tel.: +8613893378787

School of Geography and Tourism, Shaanxi Normal University

Xi'an, Shannxi 710119, China

This is the author's manuscript of the article published in final edited form as:

Wang, K., Zeng, X., Liu, X., Lanning, M., Wu, G., Zhao, L., Xu, G., Wang, Y., Zhang, L., Li, X., Lu, Q., \& Wang, L. (2020). Nitrogen rather than streamflow regulates the growth of riparian trees. Chemical Geology, 547, 119666. https://doi.org/10.1016/j.chemgeo.2020.119666 


\section{Highlights}

$>$ Tree-ring $\delta^{15} \mathrm{~N}$ increased with a rate of $0.4 \%$ per decade but nitrogen concentration remained stable during 1930-2008.

$>$ Tree-ring $\delta^{15} \mathrm{~N}$ and streamflow both showed rising trends, but they only significantly correlated over the period of 1975-1994.

$>$ The carbon and nitrogen cycling of riparian trees was associated but decoupled after 1986.

$>$ The $\delta^{15} \mathrm{~N}$ and iWUE regulated Euphrates poplar tree growth together, but they have different dominant periods. 


\section{Abstract}

In arid and semiarid regions, riparian forests are crucial for maintaining ecological biodiversity and sustainability, and supporting social and economic development. For the typical arid and semiarid ecosystem, streamflow variability is thought to be the dominant factor influencing the vulnerability and evolution of the riparian forests, which often leads to the neglect of other potentially important factors such as nutrient availability and transport. Here, we measured annual stable nitrogen isotopes $\left(\delta^{15} \mathrm{~N}\right)$ and nitrogen concentrations $(\mathrm{N} \%)$ in the tree rings of Populus euphratica Oliv. (Euphrates poplar) over a 90 year period (1920-2012), collected from the lower researches of the inland Heihe River, northwestern China. Coupling with our previous dual-isotope $\left(\delta^{13} \mathrm{C}\right.$ and $\left.\delta^{18} \mathrm{O}\right)$ chronologies and estimated intrinsic water-use efficiency (iWUE), we examined the linkages between tree-ring $\delta^{15} \mathrm{~N}$ and $\delta^{18} \mathrm{O}$, iWUE, streamflow, and then explored the contributions of each to tree growth during the study period. Our results show that after 1975, a statistically significant correlation between tree-ring $\delta^{15} \mathrm{~N}$ and river streamflow appears, indicating the river as a potential carrier of nitrogen from the upper and middle reaches to the lower research trees. In addition, the linkage between tree-ring $\delta^{15} \mathrm{~N}$ and iWUE suggests substantial influence of carbon and nitrogen together on photosynthesis and transpiration of trees, although this connection become decoupled since AD 1986. The commonality analysis revealed that the nitrogen impacts indicated by tree-ring $\delta^{15} \mathrm{~N}$ on tree growth cannot be ignored when evaluating riparian forest development. The 
fertilization effects caused by rising $\mathrm{CO}_{2}$ concentration complicate the nitrogen constraints on tree growth during the later part of the past century. Our results have potentially broad implications for identifying the limited factors for dryland forest ecosystems that are susceptible to natural water resource variations and human activities.

Key words: Tree rings; Stable isotopes; Nitrogen cycling; Riparian tree growth; Semiarid inland river

\section{Introduction}

Arid and semi-arid regions cover about $28 \%$ of the land surface. They are fragile and extremely sensitive to climate change (Huang et al., 2016; Wang et al., 2012). Human activities are projected to have profound impacts on arid and semi-arid environments which will not only have consequences for the environment, but for humans too (Charney, 1975; Dong, 2018; Huang et al., 2010; Rotenberg and Yakir, 2010; Xue, 1996; Yang et al., 2016; Zeng et al., 1999). Climate models have projected that decreased precipitation and rises in temperatures will lead to more droughts as well as more severe water shortages in the twenty-first century in mid-latittude arid and semi-arid regions (Li et al., 2017; Zhao and Dai, 2017). In such regions, inland rivers are not only valuable water resources, but also can influence terrestrial ecosystem productivity and plant growth through nutrient transport in the water supply (Peng et al., 2015). Populus euphratica Oliv. (Euphrates poplar) is the dominant tree species in riparian forests along the China's inland river, and the forests 
are crucial for maintaining ecological biodiversity in semiarid inland regions(Zhao et al., 2016). Additionally, riparian forests provide ecosystem services such as the denitrification of runoff, stream bank stabilization, erosion control, and lessening the impact of damaging floods (Liu et al., 2014; Peng et al., 2015). Despite their importance, some riparian forests have experienced significant alteration of water flux and chemical nutrients due to the agriculture activities and intensive streamflow regulation for human use upstream, such as the inland Heihe River (Guo et al., 2009; Zhao et al., 2004). Riparian forests are thus deeply influenced by human activities that alter water environmental conditions and a detailed analysis of this important connection needs to be undertaken.

The Heihe River, the second largest inland river in China, traverses arid and semiarid regions located in northwestern China (Fig. 1). It goes through semi-arid, arid, and extremely arid areas, and consequencely, it has been divided into three reaches with two valleys: Yingluoxia valley and Zhengyixia valley (Wang et al., 2018). The upper reach of the Heihe River basin (HRB) is covered by mountainous forests, shrub and grasslands, and provides nearly $70.0 \%$ of the total streamflow, which supplies irrigation water for agriculture in the middle and lower reaches (Niu et al., 2018; Wang et al., 2018). The middle reaches is the water consumptive area of the entire Heihe River, as about $92.8 \%$ oases agriculture and concentrate in the middle reaches of the Heihe River and consume about $86.9 \%$ of the water resources (Niu et al., 2018). Humans utilize river and ground water to irrigate crops, effectively transferring the water from a stable subsurface supply to streamflow which is taken 
away from the region. This has given rise to a shortage of ecological water and made ecological protection and agricultureal development in the middle reaches of the Heihe River conflicting ideas (Peng et al., 2015). The lower reaches are the most fragile ecosystems of the Heihe River with riparian forest, Gobi and desert as the main landscapes. This region is characterized by disappearing terminal lakes, shrinking oases, rapid desertification, among other issues (Liu et al., 2010; Wang et al., 2018; Wang et al., 2013). Thus, understanding the riparian forest growth dynamics is crucial to ecological safety and sustainable oasis development.

Tree-ring studies in riparian forests in the lower reaches of the Heihe have been conducted widely. For example, previous study reported that the radial growth of riparian trees was significantly correlated with the groundwater level in winter (Sun et al., 2006). Another study established the average streamflow in the middle reach of the Heihe River from 1430 to 2007 (Liu et al., 2010). In another study, annual mean temperature was revealed based on tree-ring width for the upper reaches of the HRB (Wang et al., 2016). These reports mainly focus on the relationships between tree-ring width and the hydro-climatic parameters which are generally considered the main factors impacting tree growth for riparian forests in semi-arid regions. Nitrogen inputs from agicultural sources have polluted the water resource and have changed the nitrogen avalibility to riparian forests (Yu et al., 2019a). To our knowledge, there are no studies which have shown the impacts of this on tree growth. Many researches had proved that the plant $\mathrm{N}$ isotopic signature is a powerful tool providing an integrated assessment of $\mathrm{N}$ availability (Craine et al., 2015, 2018, 2019; Elliott et al., 2019; van 
et al., 2015). For the purposes of identifying the limiting factors for riparian forest ecosystems in the Heihe River, it is very essential to explore tree-ring nitrogen isotope, which could yield quantitative information on the regularity, and mechanisms of growth variations over long time scales.

In our study, we measured the stable nitrogen isotope $\left(\delta^{15} \mathrm{~N}\right)$ and nitrogen concentrations (N\%) in tree rings from 1920 to 2012 in P. euphratica from the lower reaches of the Heihe River. Combining our previous dual-isotopes from the same sampling sites, we explored the physiological relationships of tree-ring multiple stable isotopes $\left(\delta^{15} \mathrm{~N}, \delta^{13} \mathrm{C}\right.$ and $\left.\delta^{18} \mathrm{O}\right)$ in tree rings, which could serve as records that reflect the changes of habitat environment under anthropogenic perturbations to the carbon-nitrogen coupled cycles (Bukata and Kyser, 2007). Further, we propose that the interactive physical functions of nitrogen and carbon recorded in tree-ring isotopes will have a profound influence on tree growth. Therefore, we analyzed the relative impacts of nitrogen-carbon interactions and hydrological parameters (e.g., discharge) on tree growth in riparian forests and their contributions to tree growth. We also hypothesized that the variability of tree-ring $\delta^{15} \mathrm{~N}$ is connected to agricultural nitrogen inputs, and the losses of nitrate via denitrification together with the losses of ammonia through volatilization. Our study can provide important information for assessing the dynamic of tree growth and understanding how the interactive physical functions of nitrogen-carbon linkage in respond to the rising atmosphere $\mathrm{CO}_{2}$ in semi-arid riparian ecosystems of northwestern China. 


\section{Materials and Methods}

\subsection{Study sites and climate}

The sampling site is a riparian forest near the Langxinshan Mountain $\left(100.18^{\circ} \mathrm{E}\right.$, $40.95^{\circ}$ N. Elevation: $1055 \mathrm{~m}$ a.s.1.) located in the lower reaches of the Heihe River (Fig. 1 and Fig. S1). Populus euphratica Oliv. (Euphrates poplar) is the dominant tree species in the riparian forests with a deep root system, growing in a semi-fixed aeolian sandy soil along the Heihe River of this area. It can survive extreme temperature, high salinity and severe water stress, and is therefore an important plant species to study the variation of forests in semi-arid regions.

Our study region has strong continental characteristics. According to the meteorological station Ejina $\left(101.06^{\circ} \mathrm{E}, 41.95^{\circ} \mathrm{N}\right.$. Elevation: $957 \mathrm{~m}$ a.s.1.) close to the sampling site, its mean temperature during the growing season (May to September) is approximately $22.8^{\circ} \mathrm{C}$, and increased significantly between 1960 and $2012(p<0.001)$ (Fig. S2A), and the total precipitation averaged $28.7 \mathrm{~mm}$ over the same time with a slight decreasing tendency (Fig. S2A). The standardized precipitation evaporation index (SPEI) which was calculated using the four $0.5^{\circ} \times 0.5^{\circ}$ grid data near the sampling site and varied from -4.2 to 2.6 in the growing season, significantly decreasing between 1960 and $2012(p<0.001)$ (Fig. S2C).

In an early study, the annual streamflow of the Heihe River was reconstructed based on tree-ring width (Yang et al., 2011) because of the relative short records of observation data in studied period. From the reconstruction estimated by tree-ring 
width chronology, streamflow has significantly increased between 1930 and 2008 ( $p<$ 0.01). To our knowldge, streamflow can potentially bring the nitrogen from the middle reaches to the lower reaches. Thus, the streamflow can recharge the alluvial aquifers and maintain the groundwater depth near our sampling site, and it can provide enough underground water for riparian tree growth (Xi et al. 2010).

\subsection{Sampling and sample preparation}

We obtained 44 increment cores from 22 large, mature $P$. euphratica trees growing along the river bank (Fig. 1). Detailed information about the tree core samples also can be found in Table S1 in Supporting materials (Table S1).

All of the tree cores were taken to the laboratory and processed according to the standard techniques of dendrochronology (Stokes and Smiley, 1968). First, the tree-ring widths were measured using the LINTAB 6 measuring system and were then cross-dated using the COFECHA program to verify the dating. The ultimate chronologies for the tree-ring-width index were detrended by fitting a negative exponential or linear regression curve to remove long-term growth trends using the ARSTAN software (Cook and Holmes, 1986).

According to the suggestions from our early report (Liu et al., 2015), we selected one core from each of the five trees without evident growth disturbance for tree-ring isotope analysis. The tree-ring samples were manually separated at annual resolution using a clean stainless blade for the period covering 1920-2012. The five cores were 
then pooled by year to reach a sufficient sample mass for nitrogen isotope analysis. Then corresponding ring pairs of the various cores were pooled because of the amount required for isotope analyses. Finally, the composited tree-ring samples were ground with a ball mill (Pulverisette 23, Fritsch, Idar-Oberstein, Germany) using a 200-mesh screen to produce homogenized wood subsamples.

\subsection{Isotopic measurements}

We utilized the modified Sheppard and Thompson's protocol (Sheppard and Thompson, 2000) to remove the soluble nitrogen containing compounds (e.g., resins, sap) to make the wood samples sutiable for interpretation with nitrogen isotopes. $P$ euphratica is a non-resinous species and thus the method we chose was sutiable among different choices (Bukata and Kyser, 2005; Doucet et al., 2011; Hietz et al., 2010; Sheppard and Thompson, 2000). To remove soluble resins and sap in tree rings, about $50 \mathrm{mg}$ of ground samples were placed into filter bags (ANKOM Technology, Macedon, NY, USA) and then submerged into a 1:1 mixture of toluene and ethanol for $36 \mathrm{~h}$. Then the filter bags were placed into beakers filled with acetone and soaked for $2 \mathrm{~h}$ in an ultra-sonic bath. They were then rinsed and boiled for $4 \mathrm{~h}$ in demineralized water $(\geq 18.25 \mathrm{M} \Omega \cdot \mathrm{cm})$, and dried at $50{ }^{\circ} \mathrm{C}$ in an oven.

To get the $\delta^{15} \mathrm{~N}$ and nitrogen concentration of tree rings, about $7 \mathrm{mg}$ from dry tree-ring paired samples was weighed into tin capsules and then combusted in an element analyzer (Flash IRMS EA Isolink, Germany) operating in continuous flow mode and coupled through a ConFlo VIinterface (Thermo Fisher, Bremen, Germany) 
to a gas isotope ratio mass spectrometer (Delta V Advantage, Thermo Fisher) at the Laboratory of Stable Isotope and Global Change, Shaanxi Normal University.

Instrument calibration was performed using certified reference materials USGS-55 $\left(\delta^{15} \mathrm{~N}=-0.3 \pm 0.4 \%\right.$. After each repeated measurements, the standard deviation of $\delta^{15} \mathrm{~N}$ in a laboratory standard was less than $0.18 \%$. The working standard (Qilian junipers, $\delta^{15} \mathrm{~N}=-4.5 \pm 0.5 \%$, std $\leq 0.25 \%$ o for each measurement) was analyzed after every ten to twelve samples to assess the reproducibility of the isotope measurements and normalization. When calculating the $\delta^{15} \mathrm{~N}$ values in tree rings, the possible non-linearity effects associated with small peak heights were eliminated by using sample weights that produced peak heights similar to those of the standards (same processes were applied for the analysis of the concentration of $\mathrm{N}$ ), and linear normalization to correct for instrument drift and changes in calibration gas was calculated based on two endpoints. The details of the $\mathrm{N}$ isotope analysis are given in the Supporting Materials, and information about the analysis of $\delta^{18} \mathrm{O}$, and $\delta^{13} \mathrm{C}$ were described in Liu et al. (2014).

All isotopic measurements were expressed using delta $(\delta)$ notation. Natural abundances of $\delta^{18} \mathrm{O}, \delta^{13} \mathrm{C}$ or $\delta^{15} \mathrm{~N}$ were calculated as

$$
\delta^{18} \mathrm{O}, \delta^{13} \mathrm{C} \text { or } \delta^{15} \mathrm{~N}(\%)=\left(\frac{R_{\text {sample }}}{R_{\text {standard }}}-1\right) \times 1000
$$

where $\mathrm{R}$ is the ratio of ${ }^{18} \mathrm{O} /{ }^{16} \mathrm{O},{ }^{13} \mathrm{C} /{ }^{12} \mathrm{C}$ or ${ }^{15} \mathrm{~N} /{ }^{14} \mathrm{~N}$ in the sample and standard, respectively.

iWUE $\left(\mu \mathrm{mol} \mathrm{CO}_{2} / \mathrm{mol} \mathrm{H}_{2} \mathrm{O}\right.$ ) represents the ratio of the photosynthetic uptake of $\mathrm{CO}_{2}$ through the stomata to the simultaneous transpirational loss of water through the 
stomata. It is defined as following formula:

$$
\mathrm{iWUE}=A / g_{s}=\mathrm{C}_{\mathrm{a}} \times\left[\left(1-C_{i} / C_{a}\right) / 1.6\right]
$$

where $A$ is the rate of $\mathrm{CO}_{2}$ assimilation by the leaves, $g_{s}$ is the stomatal conductance to water vapour, and $C_{i}$ and $C_{a}$ are the $\mathrm{CO}_{2}$ concentrations in the intercellular space of the leaves and in the atmosphere, respectively. To determine $C_{i}$ $/ C_{a}$, we used the equation proposed by Francey and Farquhar (Francey and Farquhar, 1982):

$$
C_{i}=C_{a} \times\left[\left(\delta^{13} \mathrm{C}_{\mathrm{p}}-\delta^{13} \mathrm{C}_{\mathrm{a}}+1\right) /(b-a)\right]
$$

where $\delta^{13} \mathrm{C}_{\mathrm{p}}$ and $\delta^{13} \mathrm{C}_{\mathrm{a}}$ refer to the $\delta^{13} \mathrm{C}$ composition of $\alpha$-cellulose and of atmospheric $\mathrm{CO}_{2}$, respectively. The parameter $a(4.4 \%)$ is the fractionation that occurs during the diffusion of $\mathrm{CO}_{2}$ from the atmosphere into the intercellular space of cells, and $b(27 \%)$ is the assumed fractionation associated with enzymatic carbon fixation.

\subsection{Data analysis}

We used a linear regression to test the temporal trends of annual climate data (temperature, precipitation, and SPEI) from 1960 to 2012 as well as $\delta^{15} \mathrm{~N}$ and streamflow data during 1930-2008 (Fig. S2 and 2A, 4A). Then, an 8-year low-pass FFT (Fast Fourier Transform) filter was used to emphasize the low-frequency variations of $\delta^{15} \mathrm{~N}$ and tree-ring width index (Fig. 2A and 2C). After that, we computed Pearson's correlation coefficient $(r)$ to examine the relationships between $\delta^{15} \mathrm{~N}$ series and tree-ring width index in 1960-2012, and $\delta^{15} \mathrm{~N}$ and streamflow in 
1930-2008 (Fig. 2C and 4A). Also, the correlation of variations of $\delta^{15} \mathrm{~N}$ and iWUE, $\delta^{15} \mathrm{~N}$ and streamflow, and $\delta^{15} \mathrm{~N}$ and $\delta^{13} \mathrm{C}$ were calculated by the 21-year moving correlation analysis using the first difference and raw data (Fig. 3C, 4B, S3C).

Factors such as carbon, climate parameters (temperature, relative humidity) and streamflow were found to be important in our previous study at the same sampling site (Liu et al., 2014), the linear mixed-effects models (LMMs) were used to determine the combination of these factors that best explained tree-ring width index. The streamflow, $\delta^{15} \mathrm{~N}, \delta^{18} \mathrm{O}$ and iWUE were considered as fixed effects in our models to test for mixed effects on tree-ring width index while "decade" was considered as random effects (Table 1 and 2). We divided the whole growth period into two parts (Table S2 and S3) because the $\mathrm{CO}_{2}$ fertilization effects were significant after 1978 (Liu et al., 2014), and we performed the p-value of each best-fitted linear-mixed models to present the significance level of individual factor in each models (Table S4 and S5). Changes in $\delta^{15} \mathrm{~N}$ exhibit strongly collinearity with other factors (especially with iWUE), which makes it difficult to separate the contributions of the two-factor proxies using simple correlation and regression analysis (Huang et al., 2017). Therefore, we further performed the commonality analysis on the same period in addition to LMM to decompose the regression effects of both predictors (streamflow, $\delta^{15} \mathrm{~N}, \delta^{18} \mathrm{O}$, and iWUE) in raw (yearly) and first difference variations and then calculate their percent contribution on tree-ring growth (Fig.5B-E, Table S6-S9). Both analyses were performed with the R software 3.5.1 (https://www.r-project.org/). The details of the linear mixed-effects models and commonality analysis are given in the 
Supporting Material.

\section{Results}

\subsection{Tree-ring $\delta^{15} \mathrm{~N}$ and nitrogen concentration}

In the riparian forests of the lower reaches, tree-ring $\delta^{15} \mathrm{~N}$ increased with a rate of 0.4\%o per decade during 1930-2008 ( $p<0.001$ ), ranging from $2.5 \%$ o to $9.6 \%$, while varied obviously during the juvenile age period between 1920-1930 (Fig. 2A). Whereas at the outermost growth period between 2008 and $2012, \delta^{15} \mathrm{~N}$ decreased sharply (Fig. 2A). In contrast to the tree-ring $\delta^{15} \mathrm{~N}$, nitrogen concentration in tree rings exhibited no clear trend over 1930-2008 (ranging from $0.05 \%$ to $0.1 \%$ ) but increased sharply during 2008-2012 with highest nitrogen concentration at the outermost growth rings (Fig. 2B). There was no obvious variation in $\delta^{15} \mathrm{~N}$ or nitrogen concentration between sapwood and heartwood boundary during 1990-1995. Tree-ring $\delta^{15} \mathrm{~N}$ and width index correspond in low frequency variations $(r=0.49, p<0.001)$ and annual extreme variations (such as in 1947,1958 and 1978), which indicate the substantial linkage of $\delta^{15} \mathrm{~N}$ to tree growth (Fig. 2C). The detailed influence and contribution of $\delta^{15} \mathrm{~N}$ to tree growth were shown in the the following results of LMMs (Table 1 and 2) and commonality analysis.

\subsection{Correlations between tree-ring $\delta^{15} \mathrm{~N}, \delta^{13} \mathrm{C}$ and iWUE}

We compared the raw data and first difference variations of tree-ring $\delta^{15} \mathrm{~N}$ with

$\delta^{13} \mathrm{C}$ (corrected with the impacts of increasing atmosphere $\mathrm{CO}_{2}$ ), and found no 
significant correlation for the raw data although there was visible correspondence in some periods such as 1976-2006 (Fig. S3A). However, a significant and positive relationship $(p<0.05)$ was observed for the first difference variations between two series (Fig. S3 A and B). As the 21-year moving correlation coefficient between $\delta^{13} \mathrm{C}$ and $\delta^{15} \mathrm{~N}$ passed the $95 \%$ confidence interval from 1954 to1974 (Fig. S3 C), we can infer that, to a certain degree, tree-ring $\delta^{15} \mathrm{~N}$ is affected by photosynthetic stimulation or stomatal conductance in that period.

Our results further revealed the positive correlations between tree-ring $\delta^{15} \mathrm{~N}$ and iWUE in the period 1930-2008 both for annual data $(p<0.001)$ and first difference data $(p<0.05)$ (Fig. 3A and B). Both $\delta^{15} \mathrm{~N}$ and iWUE increased consistently throughout the study period, and there are several asynchronous years of annual tree-ring $\delta^{15} \mathrm{~N}$ and iWUE data (Fig. 3A). The 21-year moving correlation coefficients between tree-ring $\delta^{15} \mathrm{~N}$ and iWUE increased in 1940-1953 and were significant at $p=$ 0.05 between 1954 to 1985 (Fig. 3C), suggesting the strong linkage of carbon and nitogen cycling to $P$. euphratica growth. However, this connection between two isotopes is decoupled during the past two decades.

\subsection{The contribution of each factor to tree growth}

Riparian tree-ring $\delta^{15} \mathrm{~N}$ showed a consistent increasing trend $(p<0.001)$ along with the increase of streamflow (Fig. 4A), and they were significantly correlated between 1930-2008 $(r=0.31, p<0.01)$. Except for a short period around 1960, the 21-year moving correlations indicated the primarily positive correlation between $\delta^{15} \mathrm{~N}$ 
and streamflow which became significant after 1975 for the annual data, and after 1981 for the first difference variations (Fig. 4B). Based on our data, the growth of $P$. euphratica was well correlated with multiple variables (e.g., streamflow, nitrogen, carbon, and climate factores including temperature and relative humidity) (Table.1). At the same time, we noticed that some factors which impacted the tree growth correlated with each other, for example iWUE and $\delta^{18} \mathrm{O}$ correlated significantly in 1930-1969, while $\delta^{15} \mathrm{~N}$ and iWUE have a significant correlation in $1954-1985$, also streamflow and $\delta^{15} \mathrm{~N}$ show a positive relationship in 1975-1994 (Fig. 5A). Therefore we utilized LMMs to identify the mixed and unique impact of climate factors, nitrogen and carbon cycling, and streamflow on tree growth using $\delta^{18} \mathrm{O}$ (Tsuji et al., 2006), $\delta^{15} \mathrm{~N}$, iWUE, and streamflow as proxies, respectively. It is noteworthy that the mix effects of streamflow, $\delta^{18} \mathrm{O}$, and $\delta^{15} \mathrm{~N}$ impacted tree growth significantly between 1930 and $2008(\mathrm{AIC}=-11.5, \mathrm{BIC}=2.7)$, of which model the $\delta^{15} \mathrm{~N}$ is the most significant factor $(p<0.001)$ (Table 1 and 2). Additionally, the mixed effects of $\delta^{18} \mathrm{O}$, $\delta^{15} \mathrm{~N}$ and iWUE affected tree growth significantly during 1930-1977 (AIC $=-10.3$, BIC $=0.9)\left(\right.$ Table S2 and 4), while the mix effects of streamflow, $\delta^{15} \mathrm{~N}$ and iWUE were the main factors influencing tree-ring growth after $1978(\mathrm{AIC}=-7.2, \mathrm{BIC}=1.4)$ (Table S3 and S5). The results of commonality analysis indicate that the unique contribution of tree-ring $\delta^{15} \mathrm{~N}$ to tree growth was much higher than the joint contribution between $\delta^{18} \mathrm{O}$ and iWUE both in raw and first difference variations during 1930-1977 (97.1\% and 75.5\%) (Fig. 5B and C). By contrast, the common contribution of $\delta^{15} \mathrm{~N}$ and iWUE takes up $22.6 \%$ in raw data, while the unique 
contribution of iWUE has a large part $(31.6 \%)$ in first difference variations in 1978-2008 (Fig. 5D and E).

\section{Discussion}

\subsection{Variations of tree-ring $\delta^{15} \mathrm{~N}$ and nitrogen concentration}

Climate change and increasing atmospheric $\mathrm{CO}_{2}$ concentration have often been reported to impact the forest ecosystem in the lower reaches of Heihe River (Liu et al., 2014; Sun et al., 2006; Wang et al., 2016). Other anthropogenic processes (e.g., farming), with the production of reactive nitrogen through nitrogen fertilization, can also lead to changes in nitrogen availability to the downstream ecosystems. However, with few observations in remote areas, the regional nitrogen deposition and variations can only be estimated from large-scale model, which results in large incertainties in the $\mathrm{N}$ cycle at our study site. Recent investigations suggest that the increases and decreases of $\delta^{15} \mathrm{~N}$ in tree rings can reflect alterations in $\mathrm{N}$ availability or cycling regionally (Hietz et al., 2010; Silva et al., 2016; van et al., 2015). In northwest China, there was an increase in plant $\mathrm{N}$ nutrition caused by the cumulative effects of enhanced $\mathrm{N}$ deposition (Liu et al., 2013). In our study, we found an increasing tendency of tree-ring $\delta^{15} \mathrm{~N}$, but no significant trend in nitrogen concentration (Fig. 2A and B). Based on the correlation between tree-ring $\delta^{15} \mathrm{~N}$ and streamflow (Fig. 4), we considered that the growth of the riparian species $P$. euphratica has been directly impacted by nitrogen input from midstream agricultural sources in recent years. At 
the same time, the surface-water quality standard (1.0 milligrams of nitrogen per litre) was exceeded in the Heihe River after the 1980s, with stable isotope evidence implying the contribution of agricultural and domestic sources (Yu et al., 2019a). Also the significant correlation between $\delta^{15} \mathrm{~N}$ and streamflow after 1975 marked that increased streamflow as the transport flux in the lower Heihe River brings additional $\mathrm{N}$ sources to our study site and thus contributed an increase in tree growth (Fig. 2C).

For the tree-ring $\delta^{15} \mathrm{~N}$ in our sampling site, it is the record of the $\mathrm{N}$ fractionation during the transport from soil or water to plants and changing $\mathrm{N}$-fertilizers (Elhani et al., 2005) . As discussed in previous reports (Bukata and Kyser, 2005; Guerrieri et al., 2011; Johannisson and Högberg, 1994), when the nitrogen supply to trees exceeds demand, it might lead to losses of nitrate via denitrification or leaching, or losses of ammonia through volatilization (Fig. S4 A). This change in signature is likely driven by two fundamental processes: ( I ) Nitrification may make more ${ }^{14} \mathrm{NO}_{3}{ }^{-}$than ${ }^{15} \mathrm{NO}_{3}{ }^{-}$ available to losses via denitrification and leaching, since nitrification discriminates against ${ }^{15} \mathrm{NH}_{4}{ }^{+}$; (II) Volatilization of ammonia should lead to a larger loss of ${ }^{14} \mathrm{NH}_{3}$ than of ${ }^{15} \mathrm{NH}_{3}$ as ${ }^{14} \mathrm{NH}_{3}$ will volatilize more readily (Shearer and Kohl, 1986). Indeed, higher input of nitrogen into the oasis agriculture ecosystem, including nitrogen fertilization and deposition, are expected to increase wood $\delta^{15} \mathrm{~N}$ and stimulate plant $\mathrm{N}$ availability (Guerrieri et al., 2011; Yu et al., 2019b). The leaching of nitrogen from excessive nitrogen fertilization soils is primarily in the form of $\mathrm{NO}_{3}{ }^{-}$in the middle reaches of the Heihe River, causing increases in the nitrogen concentrations of the shallow groundwater more and more serious in the lower reaches of the river (Yang 
and Su, 2008) (Fig. S6A). Accordingly, a disproportionate amount of enriched ${ }^{15} \mathrm{~N}$ may in nitrate wash off and seep into the water which would decrease the tree-ring $\delta^{15} \mathrm{~N}$ signal in living cells of 2008-2012. All these progress can change the $\delta^{15} \mathrm{~N}$ signal in the pool of plant available nitrogen (Spoelstra et al., 2010).

Despite the marked effect on $\delta^{15} \mathrm{~N}$, agricultural activities did not appear to alter tree-ring nitrogen concentration in P. euphratica. In addition, there was no noticeable shift in nitrogen concentration at the heartwood-sap wood boundary nor across the sapwood itself, for the nitrogen concentration presented in cambial cells of sapwood during maturation, and nitrogen from death cell in heartwood can be re-used or extracted potentially by trees during the growth season (Poulson et al., 1995). Yet, we observed a doubling of nitrogen concentration in the most recent years of growth (2008-2012), which is likely due to the consistent transport of nitrogen to the outside of the tree to support the metabolically active cambium (Balster et al., 2009). This trend is consistent with previous findings in red oak ( Quercus rubra) and white oak ( Quercus alba )in Ontario, Canada (Bukata and Kyser, 2005; van et al., 2015). Also, there is no sudden change of $\delta^{15} \mathrm{~N}$ at the heartwood-sap wood boundary because the shift of tree-ring $\delta^{15} \mathrm{~N}$ is more indicative of nitrogen environment perturbation than physiological transition (Ahrabian and Nowzari-Dalini, 2003; Doucet et al., 2012; van et al., 2015). Consequently, due to the redistribution of nitrogen by plants (Balster et al., 2009; van et al., 2015), the record of agricultural inputs were not preserved as changes in nitrogen concentration but are obvious in the isotope data. There are some evidences that $\mathrm{N}$ concentration in tree rings is not a suitable proxy for past conditions 
of the environmental availability of nitrogen ( Poulson et al., 1995; Doucet et al., 2011; Bukata and Kyser, 2005). And we believe that the tree-ring nitrogen isotope will be a powerful evidence to reveal the agricultural or natural nitrogen cycling in an whole drainage basin when the systematic tree-ring $\delta^{15} \mathrm{~N}$ network are analyzed in the future.

In contrast to our results, $\delta^{15} \mathrm{~N}$ is trending in the opposite direction as we observed in this study during the last century in other areas of the world including cold-temperate and tropical zones, such as the United States (Poulson et al., 1995), Canada (Kranabetter et al., 2013), Eastern Korea (Choi et al., 2005), and Mexico (Silva et al., 2015). In these cases, the decreasing trends were attributed to increased deposition of ${ }^{15} \mathrm{~N}$-depleted $\mathrm{N}$ compounds due to increased emission of $\mathrm{NO}_{\mathrm{x}}$ and $\mathrm{NH}_{3}$ (Poulson et al., 1995).

At the same time, the climate condition changes of soil temperature and $\mathrm{pH}$ value, mycorrhizal activity, relative rate of soil $\mathrm{N}$ transformation (mineralization, nitrification, ammoniation) and the $\delta^{15} \mathrm{~N}$ value of available $\mathrm{N}$ caused by climate change all affect the tree-ring $\delta^{15} \mathrm{~N}$ value (Hietz et al., 2010). At our sampling site, the increasing tree-ring $\delta^{15} \mathrm{~N}$ has a positive correlation with monthly temperature and a negative correlation with monthly precipitation during the growing season (Fig.S5), indicating that the winter temperature may partly influence the mycorrhizal activity, relative rate of soil $\mathrm{N}$ transformation (mineralization, nitrification, ammoniation) in current year (Hietz et al., 2010). This also indicates that an increasing fraction of ecosystem $\mathrm{N}$ losses are in ${ }^{15} \mathrm{~N}$-depleted forms $\left(\mathrm{NO}_{3}, \mathrm{~N}_{2} \mathrm{O}\right.$, etc. $)$, with decreasing precipitation and increasing temperature(Amundson et al., 2003). 
As of now, the global trend in tree-ring $\delta^{15} \mathrm{~N}$ (and analogously plant nitrogen sourcing) is undefined and it is important for more researches to better understand nitrogen cycling in the future.

\subsection{The carbon-nitrogen controlling to tree growth}

Previous studies have identified hydrological and climatic variables to be the dominant controls of riparian tree growth in the Heihe River basin (Liu et al., 2010; Sun et al., 2006; Wang et al., 2016). However, other studies found that such relationship was not very strong and that there must be other influences on tree growth in this area (Liu et al., 2014). As the commonality analysis shows in this study, we found that the streamflow in the lower Heihe River is not the most dominant factor for tree growth throughout the oasis (Table S6-9), because the tree-ring growth of $P$. euphratica was influenced by the level of the groundwater (Sun et al., 2006). From Fig.5a, the specific correlations between iWUE, $\delta^{18} \mathrm{O}, \delta^{15} \mathrm{~N}$ and river streamflow in different period show an obvious shift between different factors impacting tree growth. The correlation between iWUE and $\delta^{18} \mathrm{O}$ indicates the influence of climate on carbon-water balance of $P$. euphratica (Liu et al., 2014); the significant relationship between iWUE and $\delta^{15} \mathrm{~N}$ implies strong connections of the nitrogen-carbon cycling (Fig. 3); and significant correlation of river streamflow and $\delta^{15} \mathrm{~N}$ suggest nitrogen transportation through the water-source movement which is corresponding to increased tree growth rate (Fig. 4A). To tree growth variations (Fig. 5A), the detailed information about the correlations between the factors (e.g., 
streamflow, $\delta^{15} \mathrm{~N}$, iWUE, $\left.\delta^{18} \mathrm{O}\right)$ which all significantly influence the tree growth accurately describe the process impacting tree growth in different periods.

The commonality analysis model was applied to quantify the relative contributions of each predictor to the overall variance and to avoid co-linearity and interactive effects among the varaibles included in the model. As we expected, the results of commonality analysis support the hypothesis that nitrogen is one of the most influential factors in recent riparian tree growth, but the synchronous common influence of carbon also can not be ignored in the latest few years (Fig. 5D-E). In the early period (1930-1977), the iWUE remained relatively stable with a slight decrease of $C_{\mathrm{i}} / C_{\mathrm{a}}$ (Liu et al., 2014), the nitrogen supply had the dominating unique effects on tree growth (explained about $97.1 \%$ and $75.5 \%$ for annual and first difference variance ) while the unique effects of iWUE still contributed little to tree growth (Fig. 5D-E). At the same time, the impacts of tree-ring $\delta^{18} \mathrm{O}$ (as the proxy of climates contribution) was expressed at the annual variations about $23.1 \%$ (Fig. 5B). In addition, we can not ignore the combined effects of factors, such as the common effects of $\delta^{15} \mathrm{~N}$ and $\delta^{18} \mathrm{O}$, which indicate the influence of the nitrogen under climate changes on tree growth. For the later period with significant $\mathrm{CO}_{2}$ fertilization (1978-2008), the impact of nitrogen to tree growth was concealed by the contribution of rising atmosphere $\mathrm{CO}_{2}$, and the jointed effects of nitrogen and iWUE increased from $-0.7 \%$ to $22.6 \%$ and from $1.2 \%$ to $28.3 \%$ for annual and first difference variations respectively (Fig. 5B-E), suggesting the shift from $\delta^{15} \mathrm{~N}$ dominant to iWUE- $\delta{ }^{15} \mathrm{~N}$ co-dominant period to tree growth. While the common effects of 
streamflow and $\delta^{15} \mathrm{~N}$ took up $19.9 \%$ and $6.2 \%$ of annual and first difference variations respectively, demonstrating the transport of nitrogen through streamflow. These results are consistent with a report of an alpine forest from the Mexico (Silva et al., 2016), where tree growth may have been stimulated by the integrated effects of $\mathrm{CO}_{2}$ fertilization, increase water and enhanced nitrogen.

Variations in tree growth at our study site can be explained by different multiple parameters cover the whole investigated time. The oasis agricultural nitrogen in the middle reach increased the $\mathrm{N}$ in the water, which provided the nutrition to the plant along the lower reaches and affected tree-ring growth before 1980s (Fig. 5). The increasing $\mathrm{N}$ obtained by the riparian trees can enrich the protein, promote the enzyme activities, increase the chlorophyll in plant (Beghin et al., 2011). For this reason, nitrogen can contribute to the plant physical process, such as photosynthesis. As suggested in our previous investigation, $\mathrm{CO}_{2}$ fertilization effects on tree growth have been detected in arid environments in 1978 with the enrichment of atmosphere $\mathrm{CO}_{2}$ (Liu et al., 2014). With the increase cropland $\mathrm{N}$ in Heihe River nearly from $0.2 \mathrm{t} \mathrm{km} 2$ to $1.3 \mathrm{t} \mathrm{km}^{2}$ (Yu et al., 2019), and the water quality over the area fall from level $\mathrm{I}$ to III during the period of 1984-1994. In this period, nitrogen availability strongly regulates the plant growth in response to increasing $\mathrm{CO}_{2}$ (He et al., 2017; Norby et al., 2010; Peñuelas et al., 2017), which would complicate the $\mathrm{CO}_{2}$ fertilization to an amount under water limited conditions after 1978 (Balster et al., 2009; He et al., 2017; Norby et al., 2010). Gradually, the combination of nitrogen supply and $\mathrm{CO}_{2}$ fertilization become the controlling factors to tree growth (Fig.5). The repeated 
observations found that nitrogen inputs increase iWUE for the addition of nitrogen especially in the dry condition, which would give rise to $\mathrm{CO}_{2}$ assimilation $(A)$ increased or stomatal conductance $(g s)$ decreased and contribute to tree growth (Leonardi et al., 2012; Livingston et al., 1999). Also, the need to maintain transpiration to increase mass flow of nitrogen to the root system is reduced, which leads to an increase iWUE (Cramer et al., 2008).However, the enhanced photosynthesis or photosynthetic capacity by $\mathrm{CO}_{2}$ fertilization and nitrogen supply may not always result in the increased tree growth rate due to the negative impacts caused by unfavorable tree growth environments.

Unfortunately, we lack the direct $\delta^{15} \mathrm{~N}$ evidence of isotope in roots and leaves of tress, which could be helpful to understand the primarily physiological response of iWUE to drought or changed nitrogen input. We speculate that the photosynthesis of plants is closely related to nitrogen concentration changes in roots and leaves. At the same time, the uptake of nitrogen by plant roots and the transport of nitrogen to plant tissue require the energy provided by the mass flow which is modulated by transpiration (Cramer et al., 2008). For this reason, the interactive physical functions of nitrogen and carbon will occur across scales, such as cellular, tissue, organ, individual, ecosystem and even region, which is essential to understand detailedly the tree growth dynamics in response to changes of water and ecological environment in inland Heihe River (Fig. S6B). A more extensive analysis about the above issues thus should be strengthened in further study. 


\section{Conclusion}

In this study, we explored the trend of tree-ring $\delta^{15} \mathrm{~N}$, and its response to streamflow, along with other factors affecting riparian tree growth. Tree-ring $\delta^{15} \mathrm{~N}$ displayed an increasing trend, which is significantly correlated with the streamflow over the period 1975-1994. Other tree-ring isotopes, such as $\delta^{13} \mathrm{C}$, also have a significant correlation with $\delta^{15} \mathrm{~N}$, indicating a substantial connection between nitrogen and carbon cycles, and this information is reflected in tree-ring isotopes. Nitrogen contributes more to riparian tree growth relative to other factors (iWUE, streamflow, $\delta^{18} \mathrm{O}$ ) during 1930-1977, while the mixed effects of iWUE and $\delta^{15} \mathrm{~N}$ played an important role during the period from 1978 to 2008. These phenomena mean that nitrogen is the main factor regulating riparian tree growth although others factors also contribute to tree growth in lower reaches of the semiarid inland Heihe River. In further studies, it is essential to focus on the potential influence of nitrogen on tree radial growth along the inland river for all the semi-arid and arid areas utilizing the information recorded in tree-ring nitrogen isotopes.

\section{Acknowledge}

This research was supported by the National Natural Science Foundation of China (41971104 \& 41807431) and by the Fundamental Research Funds for the Central Universities (GK201801007) and by National Science Foundation of Shaanxi 
Province (2019JQ-325) and by the open foundation of the State Key Laboratory of Loess and Quaternary Geology, Institute of Earth Environment (CASSKLLQG1817). LW acknowledges partial support from Division of Earth Sciences of National Science Foundation (NSF EAR- 1562055)

\section{References}

Ahrabian, H., Nowzari-Dalini, A., 2003. Potential for assessing long-term dynamics in soil nitrogen availability from variations in $\delta^{15} \mathrm{~N}$ of tree rings. Isot Environl Healt S, 39(1): 15-28.

Amundson, R., Austin, A. T., Schuur, E. A., Yoo, K., Matzek, V., Kendall, C., ... \& Baisden, W. T. 2003. Global patterns of the isotopic composition of soil and plant nitrogen. Global biogeochemical cycles, 17(1).

Balster, N.J., Marshall, J.D., Clayton, M., 2009. Coupling tree-ring $\delta^{13} \mathrm{C}$ and $\delta^{15} \mathrm{~N}$ to test the effect of fertilization on mature Douglas-fir (Pseudotsuga menziesii var. glauca) stands across the Interior northwest, USA. Tree Physiol, 29(12): 1491.

Beghin, R., Cherubini, P., Battipaglia, G., Siegwolf, R., Saurer, M., \& Bovio, G. 2011. Tree-ring growth and stable isotopes $(\delta 13 \mathrm{C}$ and $\delta 15 \mathrm{~N})$ detect effects of wildfires on tree physiological processes in Pinus sylvestris L. Trees, 25(4), 627-636.

Bukata, A.R., Kyser, T.K., 2005. Response of the nitrogen isotopic composition of tree-rings following tree-clearing and land-use change. Environ Sci Technol, 39(20): 7777-7783.

Bukata, A.R., Kyser, T.K., 2007. Carbon and nitrogen isotope variations in tree-rings as records of perturbations in regional carbon and nitrogen cycles. Environ Sci Technol, 41(4): 1331-8.

Charney, J.G., 1975. Dynamics of deserts and drought in the Sahel. Q. J. R. Meteorol. Soc, 101(428): 193-202.

Choi, W.-J., Lee, S.-M., Chang, S.X., Ro, H.-M., 2005. Variations of $\delta^{13} \mathrm{C}$ and $\delta^{15} \mathrm{~N}$ in Pinus densiflora tree-rings and their relationship to environmental changes in 
eastern Korea. Water, Air, and Soil Poll, 164(1-4): 173-187.

Cook, E., Holmes, R., 1986. Users Manual for Program ARSTAN. Laboratory of Tree-Ring Research. Tucson, USA: University of Arizona.

Craine, J. M., Brookshire, E. N. J., Cramer, M. D., Hasselquist, N. J., Koba, K., Marin-Spiotta, E., \& Wang, L., 2015. Ecological interpretations of nitrogen isotope ratios of terrestrial plants and soils. Plant and Soil, 396(1-2), 1-26. doi:10.1007/s11104-015-2542-1

Craine, J. M., Elmore, A. J., Wang, L., Aranibar, J., Bauters, M., Boeckx, P., ... Zmudczyńska-Skarbek, K., 2018. Isotopic evidence for oligotrophication of terrestrial ecosystems. Nature Ecology \& Evolution, 2(11), 1735-1744.

Craine, J.M. et al., 2019. Reply to: Data do not support large-scale oligotrophication of terrestrial ecosystems. Nat Ecol Evol: 1-2.

Cramer, M.D., Hoffmann, V., Verboom, G.A., 2008. Nutrient availability moderates transpiration in Ehrharta calycina. New Phytol, 179(4): 1048-1057.

Dong, G., 2018. Understanding past human-environment interaction from an interdisciplinary perspective. Sci. Bull, 63(16): 1023-1024.

Doucet, A., Savard, M.M., Bégin, C., Smirnoff, A., 2011. Is wood pre-treatment essential for tree-ring nitrogen concentration and isotope analysis? Rapid Commun Mass Sp, 25(4): 469-475.

Doucet, A., Savard, M.M., Bégin, C., Smirnoff, A., 2012. Tree-ring $\delta^{15} \mathrm{~N}$ values to infer air quality changes at regional scale. Chem Geol, 320: 9-16.

Elhani, S., Guehl, J. M., Nys, C., Picard, J. F., \& Dupouey, J. L., 2005. Impact of fertilization on tree-ring $\delta^{15} \mathrm{~N}$ and $\delta^{13} \mathrm{C}$ in beech stands: a retrospective analysis. Tree physiology, 25(11), 1437-1446.

Elliott, E.M., Yu, Z., Cole, A.S., Coughlin, J.G., 2019. Isotopic advances in understanding reactive nitrogen deposition and atmospheric processing. Sci Total Environ, 662: 393-403.

Francey, R., Farquhar, G., 1982. An explanation of ${ }^{13} \mathrm{C} /{ }^{12} \mathrm{C}$ variations in tree rings. Nature, 297(5861): 28.

Guerrieri, R. et al., 2011. The legacy of enhanced $\mathrm{N}$ and S deposition as revealed by the combined analysis of $\delta^{13} \mathrm{C}, \delta^{18} \mathrm{O}$ and $\delta^{15} \mathrm{~N}$ in tree rings. Global Change Biol, 17(5): 1946-1962.

Guo, Q., Feng, Q., Li, J., 2009. Environmental changes after ecological water conveyance in the lower reaches of Heihe River, Northwest China. Environ 
Geol 58(7): 1387.

He, L. et al., 2017. Nitrogen availability dampens the positive impacts of $\mathrm{CO}_{2}$ fertilization on terrestrial ecosystem carbon and water cycles. Geophys Res Lett, 44(22): 11,590-11,600.

Hietz, P., Dünisch, O., Wanek, W., 2010. Long-Term trends in Nitrogen isotope composition and Nitrogen concentration in Brazilian Rainforest trees suggest changes in Nitrogen cycle. Environ Sci Technol, 44(4): 1191-1196.

Högberg, P., Tamm, C.-O., Högberg, M., 1992. Variations in ${ }^{15} \mathrm{~N}$ abundance in a forest fertilization trial: Critical loads of $\mathrm{N}, \mathrm{N}$ saturation, contamination and effects of revitalization fertilization. Plant Soil, 142(2): 211-219.

Huang, J. et al., 2016. Global semi-arid climate change over last 60 years. Clim. Dyn, 46(3-4): 1131-1150.

Huang, J. et al., 2010. Dust aerosol effect on semi-arid climate over Northwest China detected from A-Train satellite measurements. Chem Phys, 10(14): 6863-6872.

Huang, R. et al., 2017. Does increasing intrinsic water use efficiency (iWUE) stimulate tree growth at natural alpine timberline on the southeastern Tibetan Plateau? Global Planet Change, 148: 217-226.

Johannisson, C., Högberg, P., 1994. ${ }^{15} \mathrm{~N}$ abundance of soils and plants along an experimentally induced forest nitrogen supply gradient. Oecologia, 97(3): 322-325.

Kranabetter, J.M., Saunders, S., Mackinnon, J.A., Klassen, H., 2013. An assessment of contemporary and historic nitrogen availability in contrasting coastal Douglas-fir forests through $\delta^{15} \mathrm{~N}$ of tree rings. Ecosystems, 16(1): 111-122.

Leonardi, S. et al., 2012. Assessing the effects of nitrogen deposition and climate on carbon isotope discrimination and intrinsic water- use efficiency of angiosperm and conifer trees under rising $\mathrm{CO}_{2}$ conditions. Glob Change Biol, 18(9): 2925-2944.

Li, C., Zhao, T., Ying, K., 2017. Quantifying the contributions of anthropogenic and natural forcings to climate changes over arid-semiarid areas during 1946-2005. Clim. Change, 144(3): 505-517.

Liu, X. et al., 2015. Pooled versus separate tree-ring $\delta \mathrm{D}$ measurements, and implications for reconstruction of the Arctic Oscillation in northwestern China. Sci Total Environ, 511: 584-594.

Liu, X. et al., 2014. Tree growth and intrinsic water-use efficiency of inland riparian forests in Northwestern China: evaluation via $\delta^{13} \mathrm{C}$ and $\delta^{18} \mathrm{O}$ analysis of tree 
rings. Tree Physiol, 34(9): 966-80.

Liu, X. et al., 2013. Enhanced nitrogen deposition over China. Nature, 494: 459.

Liu, Y. et al., 2010. Tree-ring hydrologic reconstructions for the Heihe River watershed, western China since AD 1430. Water Res, 44(9): 2781-92.

Livingston, N., Guy, R., Sun, Z., Ethier, G., 1999. The effects of nitrogen stress on the stable carbon isotope composition, productivity and water use efficiency of white spruce (Picea glauca (Moench) Voss) seedlings. Plant Cell Environ, 22(3): 281-289.

Niu, J., Qi, L., Kang, S., Zhang, X., 2018. The response of crop water productivity to climatic variation in the upper-middle reaches of the Heihe River basin, Northwest China. J Hydrol, 596: 909-926.

Norby, R.J., Warren, J.M., Iversen, C.M., Medlyn, B.E., McMurtrie, R.E., 2010. $\mathrm{CO}_{2}$ enhancement of forest productivity constrained by limited nitrogen availability. P Natl Acad Sci USA, 107(45): 19368-19373.

Peng, X. et al., 2015. Human activity impacts on the stem radial growth of Populus euphratica riparian forests in China's Ejina Oasis, using tree-ring analysis. Trees, 31(2): 379-392.

Peñuelas, J. et al., 2017. Shifting from a fertilization-dominated to a warming-dominated period. Nat. Ecol. Evol, 1(10): 1438.

Poulson, S.R., Chamberlain, C.P., Friedland, A.J., 1995. Nitrogen isotope variation of tree rings as a potential indicator of environmental change. Chem Geol, 125(3): 307-315.

Rotenberg, E., Yakir, D., 2010. Contribution of semi-arid forests to the climate system. Science, 327(5964): 451-454.

Shearer, G., Kohl, D.H., 1986. $\mathrm{N}_{2}$-fixation in field settings: estimations based on natural ${ }^{15} \mathrm{~N}$ abundance. Funct Plant Biol 13(6): 699-756.

Sheppard, P.R., Thompson, T.L., 2000. Effect of Extraction Pretreatment on Radial Variation of Nitrogen Concentration in Tree Rings. J Environ Qual, 29(6): 2037-2042.

Silva, L.C. et al., 2016. Tree growth acceleration and expansion of alpine forests: The synergistic effect of atmospheric and edaphic change. Science advances, 2(8): e1501302.

Silva, L.C.R., Gómez-Guerrero, A., Doane, T.A., Horwath, W.R., 2015. Isotopic and nutritional evidence for species- and site- specific responses to $\mathrm{N}$ deposition 
and elevated $\mathrm{CO}_{2}$ in temperate forests. J Geophysl Res-Biogeo, 120(6): $1110-1123$.

Spoelstra, J., Schiff, S., Semkin, R., Jeffries, D., Elgood, R., 2010. Nitrate attenuation in a small temperate wetland following forest harvest. Forest Ecol and Manag, 259(12): 2333-2341.

Stokes, M., Smiley, T., 1968. 1968: An introduction to tree-ring dating. Chicago: University of Chicago Press.

Sun, J.-Y. et al., 2006. Climatic and hydrological changes on Ejin, Inner Mongolia, China during the past 233 years recorded in tree-rings of Populus euphratica. Quat Sci, 26(5): 799-809. (in Chinese)

Tsuji, H., Nakatsuka, T., Takagi, K., 2006. $\delta 18 \mathrm{O}$ of tree-ring cellulose in two species (spruce and oak) as proxies of precipitation amount and relative humidity in northern Japan. Chem Geol, 231(1): 67-76.

van, der Sleen, P. et al., 2015. ${ }^{15} \mathrm{~N}$ in tree rings as a bio-indicator of changing nitrogen cycling in tropical forests:an evaluation at three sites using two sampling methods. Front Plant Sci, 6: 229.

Wang, L., P. D’Odorio, JP Evans, D Eldridge, M. McCabe, K. Caylor and E. King. 2012. Dryland ecohydrology and climate change: critical issues and technical advances. Hydrology and Earth System Sciences 16:2585-2603.

Wang, L., Wang, Z., Yu, J., Zhang, Y., Dang, S., 2018. Hydrological Process Simulation of Inland River Watershed: A Case Study of the Heihe River Basin with Multiple Hydrological Models. Water, 10(4): 421.

Wang, P., Yu, J., Zhang, Y., Liu, C., 2013. Groundwater recharge and hydrogeochemical evolution in the Ejina Basin, northwest China. J Hydrol, 476: 72-86.

Wang, Y., Feng, Q., Kang, X., 2016. Tree-ring-based reconstruction of temperature variability (1445-2011) for the upper reaches of the Heihe River Basin, Northwest China. J Arid Land, 8(1): 60-76.

Xi, H., Feng, Q., Si, J., Chang, Z., \& Cao, S. 2010. Impacts of river recharge on groundwater level and hydrochemistry in the lower reaches of Heihe River Watershed, northwestern China. Hydrogeology Journal, 18(3), 791-801.

Xue, Y., 1996. The impact of desertification in the Mongolian and the Inner Mongolian grassland on the regional climate. J. Clim., 9(9): 2173-2189.

Yang, B., Qin, C., Shi, F., Sonechkin, D.M., 2011. Tree ring-based annual streamflow reconstruction for the Heihe River in arid northwestern China from AD 575 
and its implications for water resource management. Holocene, 22(7): 773-784.

Yang, R., Su, Y., 2008. Groundwater nitrate pollution in the oasis agricultural areas in the middle reaches of Heihe River, Northwest China. Journal of glaciology and geocryology, 30(6): 983-990.(in Chinese)

Yang, S. et al., 2016. Global warming projections using the human-earth system model BNU-HESM1.0. Sci. Bull, 61(23): 1833-1838.

Yu, C. et al., 2019a. Managing nitrogen to restore water quality in China. Nature, 567(7749): 516.

Yu, G. et al., 2019b. Stabilization of atmospheric nitrogen deposition in China over the past decade. Nat Geosci 12(6): 424.

Zeng, N., Neelin, J.D., Lau, K.-M., Tucker, C.J., 1999. Enhancement of interdecadal climate variability in the Sahel by vegetation interaction. Science, 286(5444): 1537-1540.

Zhao, L., L. Wang, L. Cernusak, X. Liu, H. Xiao, M. Zhou, S. Zhang. 2016. Significant difference in hydrogen isotope composition between xylem and tissue water in Populus euphratica. Plant Cell \& Environment

Zhao, T., Dai, A., 2017. Uncertainties in historical changes and future projections of drought. Part II: model-simulated historical and future drought changes. Clim Change, 144(3): 535-548.

Zhao, W., Chang, X., He, Z., 2004. Responses of distribution pattern of desert riparian forests to hydrologic process in Ejina oasis. Sci China Ser D, 47(1): 21-31. 


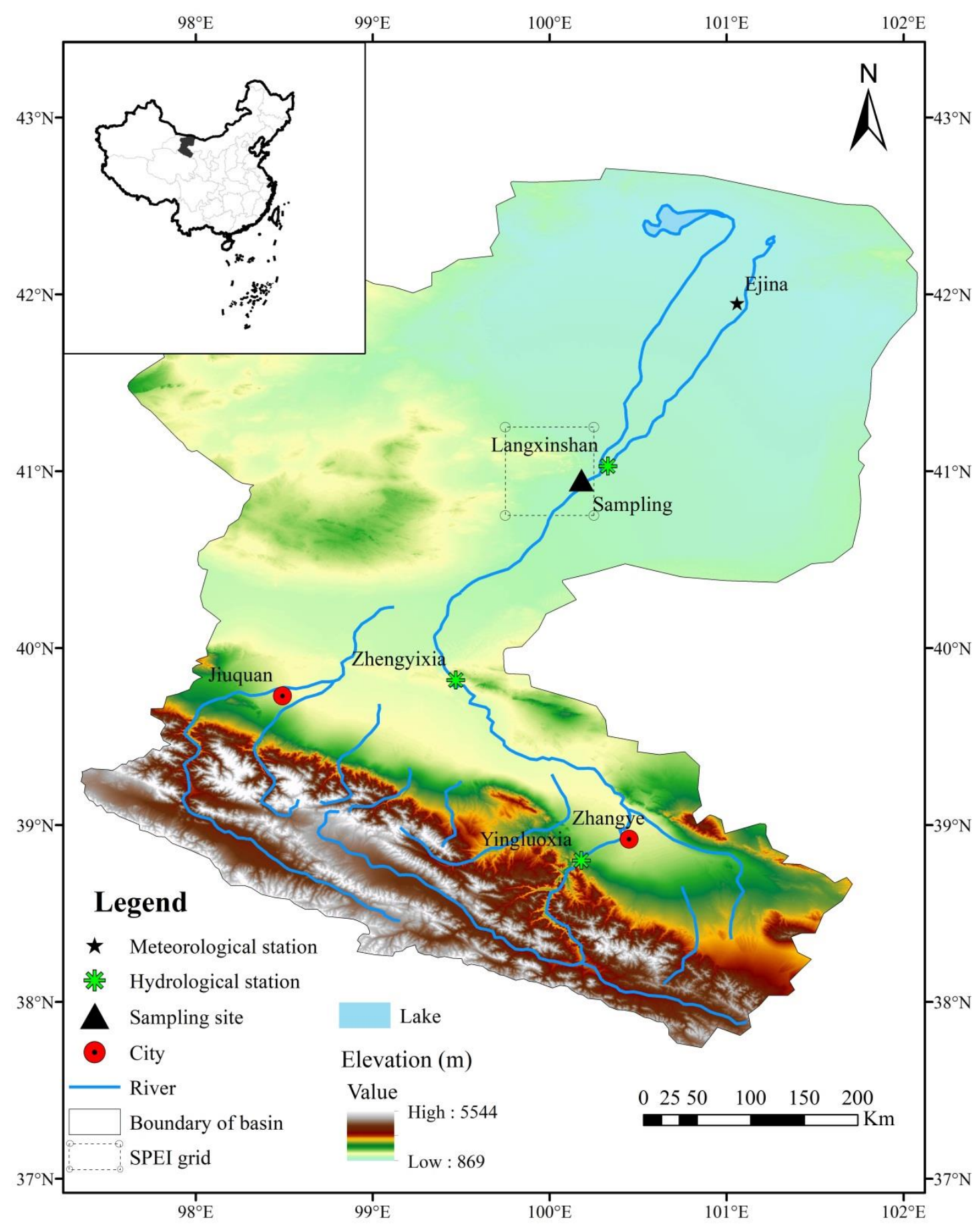

Fig.1 Map showing the location of the tree-ring sampling site, meteorological station and SPEI grid data (dashed square) used in this study. 

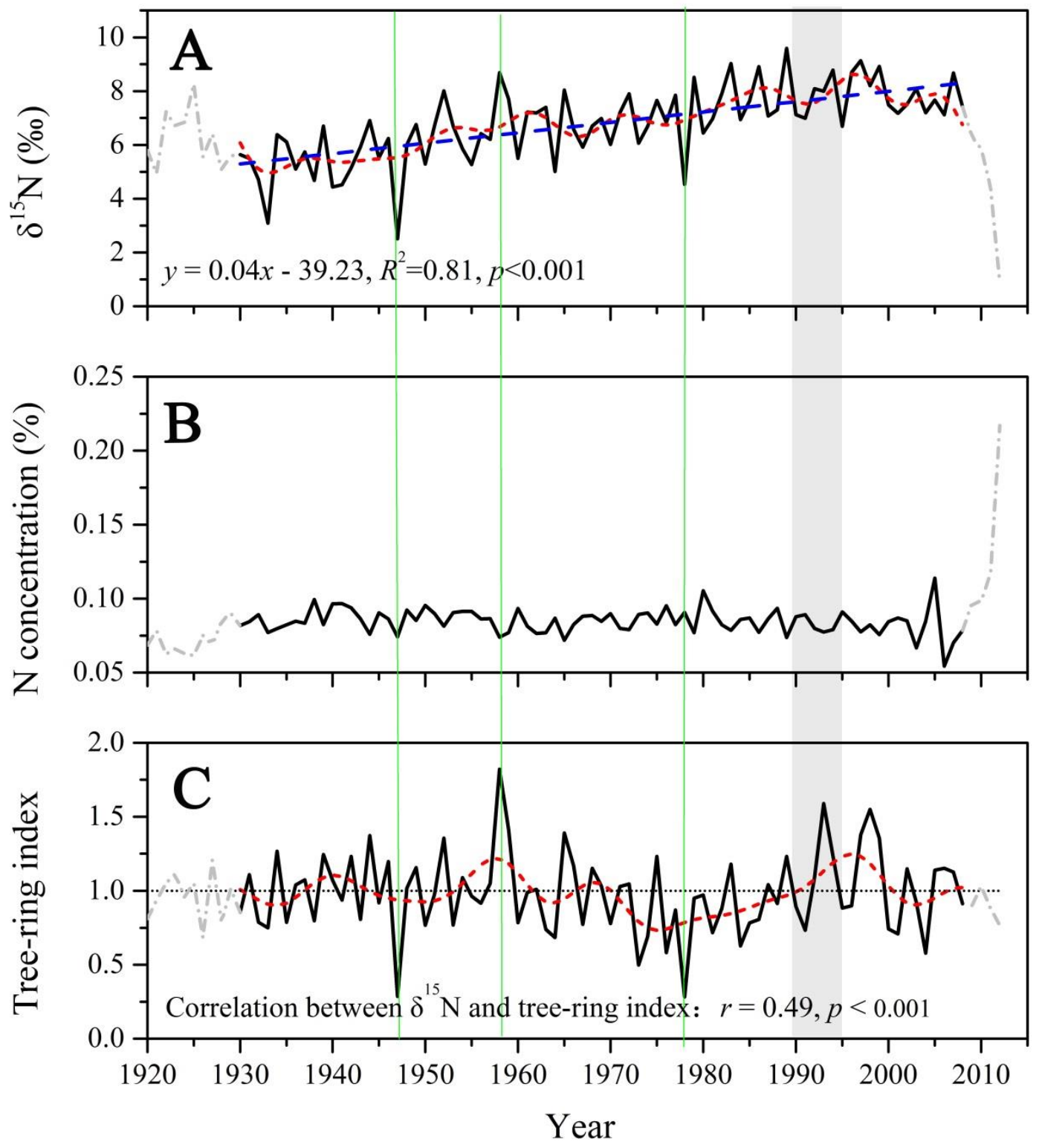

Fig. 2 Temporal variability of the $\delta^{15} \mathrm{~N}$ values (A) and nitrogen concentration (B) in tree-rings from Populus Euphratica Oliv, and the standard ring-width index (C) during 1920-2012. The juvenile period and the outermost growth period represent in grey dash dot line and mature stage represted in black line, respectively. The grey shaded region around 1990-1995 indicates the heartwood-sapwood boundry, during which most of boundary of selected samples fluctuate. The red curves were smoothed using an 8-year low-pass FFT filter to emphasize the low-frequency variations ( $A \& C$ ), and the dashed blue line represents the linear fitting of smoothed curves from 1930-2008 (A). The green vertical lines indicate the good correspondence of $\delta^{15} \mathrm{~N}$ and ring-width index at extreme annual varations. 

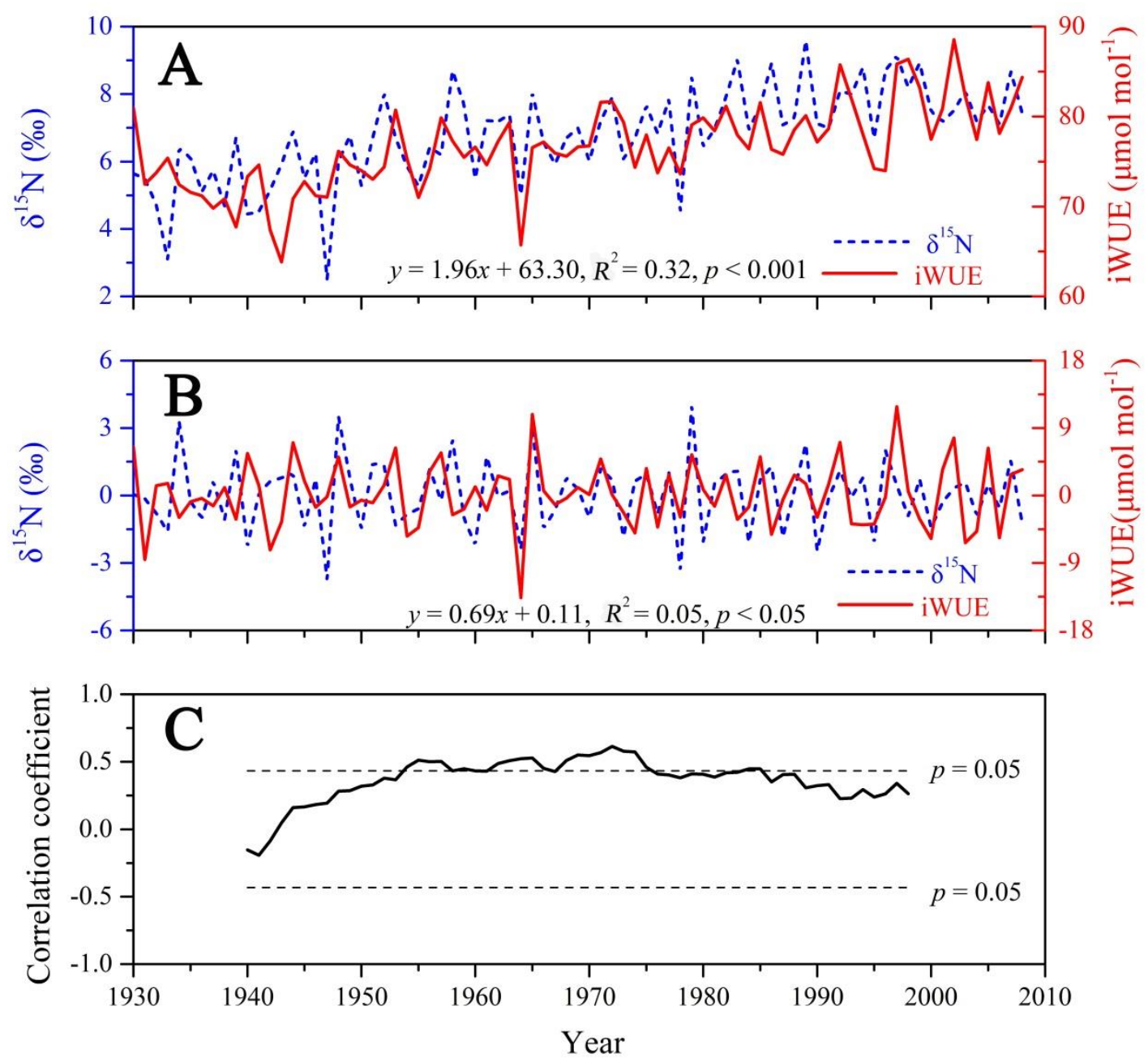

Fig. 3 (A) Temporal variability of $\delta^{15} \mathrm{~N}$ and iWUE estimated from tree-ring $\delta^{13} \mathrm{C}$ of Populus euphratica Oliv from 1930 to 2008. The comparison of $\delta^{15} \mathrm{~N}$ and iWUE at the first difference variations (B) and the 21-year moving correlations between $\delta^{15} \mathrm{~N}$ and iWUE (C). The horizontal dashed lines represent the $95 \%$ confidence intervals in panel C. The relationship between $\delta^{15} \mathrm{~N}$ and iWUE and their statistical parameters were presented in panel A and B. 


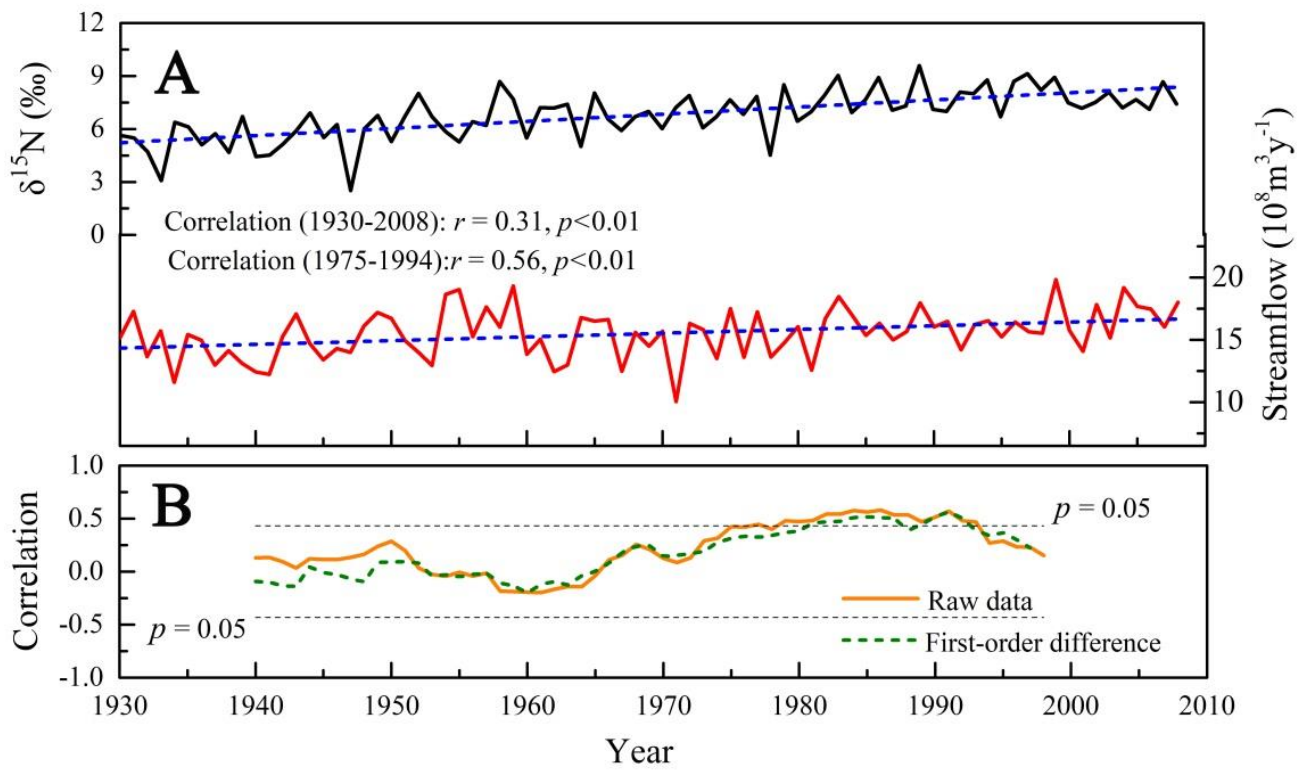

Fig. 4 (A) Linear trends of the annnal streamflow $\left(\mathrm{y}=0.03 \mathrm{x}-43.25, R^{2}=0.11, p<0.01\right)$ and tree-ring $\delta^{15} \mathrm{~N}$ during 1930-2008, and the correlation between $\delta^{15} \mathrm{~N}$ and streamflow in 1930-2008 and 1975-1994 was presented. (B) the 21-year moving correlations of $\delta^{15} \mathrm{~N}$ and streamflow of their annual and first difference variations. The annnal streamflow of Heihe River was reconstructed based on tree-ring width during the period of 1920-2008 (Yang et al., 2011). 

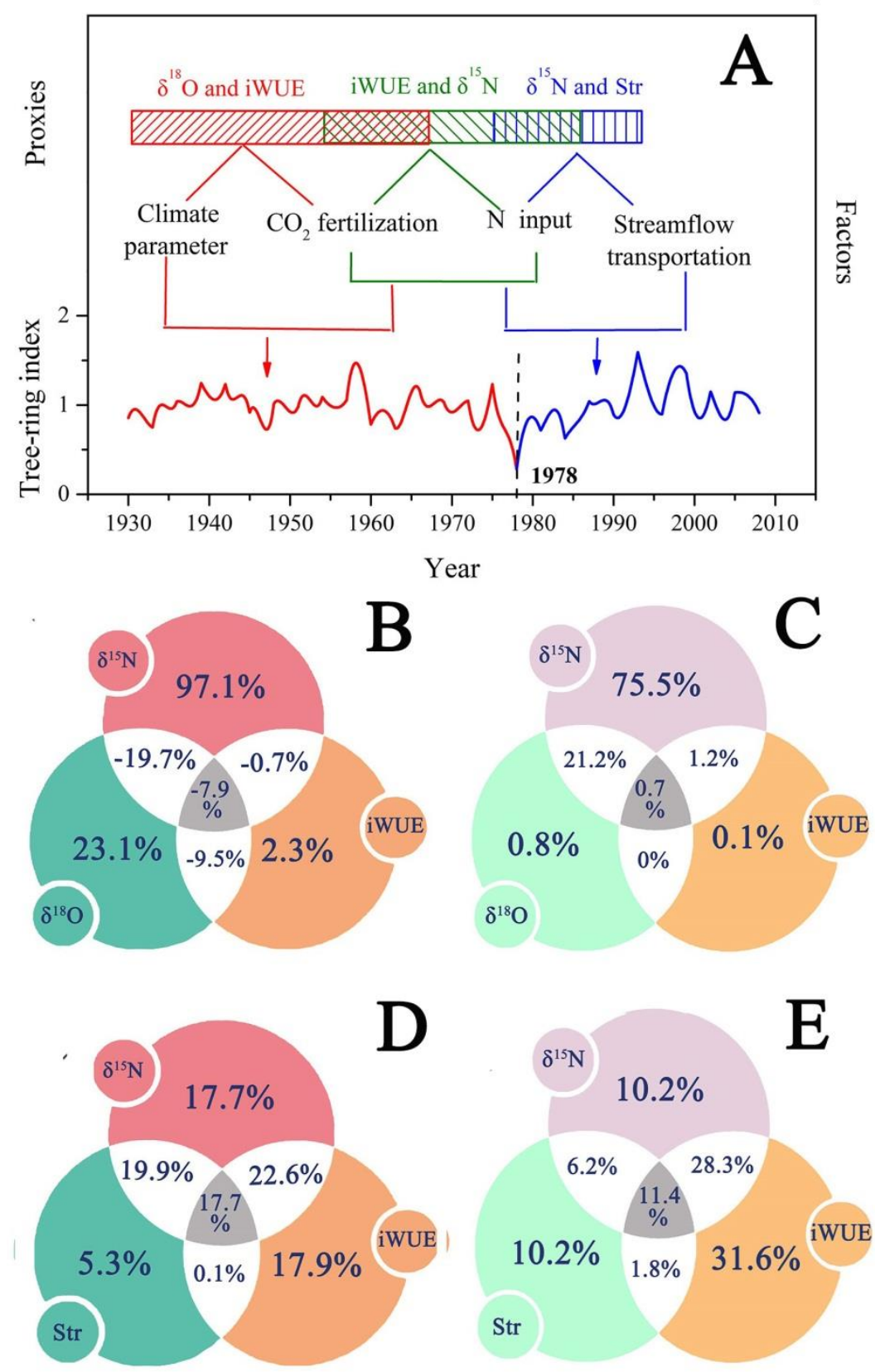

Fig. 5 To investigate the factors which impacted the tree growth, we collected the proxies of each factor, and finding the remarkable periods when the proxies significantly correlated: $\delta^{18} \mathrm{O}$ and iWUE in 1930-1969; $\delta^{15} \mathrm{~N}$ and iWUE in 1954-1985; $\delta^{15} \mathrm{~N}$ and streamflow in 1975-1994.Therefore the linear mixed-effects models are constructed to explore the combination of controlling factors to tree-ring growth covering the whole investigated time, and the results revealed that $\delta^{18} \mathrm{O}$, iWUE, and $\delta^{15} \mathrm{~N}$ are the controlling proxies in $1930-1977$ while the iWUE, $\delta^{15} \mathrm{~N}$ and streamflow in 
1978-2008 (A). The contribution of each factor (in the form of \%) to tree-ring growth analyzed by commonality analysis for the raw data and first-difference data respectively (B \& C) during 1930-1977 and (D \& E) during 1978-2008, and Str represents the streamflow in the panel A, B \& E.

Table 1 Summary of linear-mixed effects models performed to study the effects on tree-ring width index during 1930-2008. DF indicates degree of freedoms, and logLik indicates the likelihood value were log-transformed. $\Delta_{\mathrm{i}} \mathrm{AIC}\left(\Delta_{\mathrm{i}} \mathrm{BIC}\right)$ are Akaike Information Criterion (Bayesian information criterion) values corrected for small sample sizes, and wi are Akaike weights (or BIC model weights). The $\mathrm{O}, \mathrm{N}$, iWUE, str indicate $\delta^{18} \mathrm{O}, \delta^{15} \mathrm{~N}$, intrinsic water-use efficiency, streamflow, respectively. The best fit model relative to others was shown in bold font and provided in Table 2.

\begin{tabular}{lcccccccc}
\hline Model & DF & logLik & AIC & $\begin{array}{c}\boldsymbol{\Delta}_{\mathbf{i}} \\
(\mathbf{A I C})\end{array}$ & $\begin{array}{c}\mathbf{W}_{\mathbf{i}} \\
(\mathbf{A I C})\end{array}$ & $\mathbf{B I C}$ & $\begin{array}{c}\boldsymbol{\Delta}_{\mathbf{i}} \\
(\mathbf{B I C})\end{array}$ & $\begin{array}{c}\mathbf{W}_{\mathbf{i}} \\
(\mathbf{A I C})\end{array}$ \\
\hline str + N + iWUE + O & 72 & 11.8 & -9.6 & 1.9 & 0.14 & 6.9 & 4.2 & 0.06 \\
str + N + iWUE & 73 & 11 & -10 & 1.5 & 0.17 & 4.2 & 1.5 & 0.22 \\
str*N* iWUE & 69 & 14.3 & -8.7 & 2.8 & 0.09 & 15 & 12.3 & 0 \\
str + N + O & $\mathbf{7 3}$ & $\mathbf{1 1 . 8}$ & $\mathbf{- 1 1 . 5}$ & $\mathbf{0}$ & $\mathbf{0 . 3 5}$ & $\mathbf{2 . 7}$ & $\mathbf{0}$ & $\mathbf{0 . 4 6}$ \\
str*N*O & 6 & 13 & -6 & 5.5 & 0.02 & 17.7 & 15 & 0 \\
$\mathrm{~N}+\mathrm{iWUE}+\mathrm{O}$ & 73 & 11.2 & -10.4 & 1.1 & 0.20 & 3.8 & 1.1 & 0.27 \\
$\mathrm{~N} * \mathrm{iWUE} * \mathrm{O}$ & 69 & 13.1 & -6.3 & 5.2 & 0.03 & 17.4 & 14.7 & 0 \\
\hline
\end{tabular}


Table 2 The results of best fit model during the period of 1930-2008. $P$-value in fourth column indicate the confidence level (ns, $p>0.05 ; *, p<0.05 ; * *, p<0.01 ; * * *, p<0.001)$

\begin{tabular}{llll}
\hline AIC & BIC & logLik & DF \\
\hline-11.5 & 2.7 & 11.8 & 73 \\
& Estimate & SE & $\boldsymbol{p}$ \\
Intercept & -1.79892 & 0.93446 & $\mathrm{~ns}$ \\
Streamflow & 0.01401 & 0.01244 & $\mathrm{~ns}$ \\
$\boldsymbol{\delta}^{\mathbf{1 5}} \mathbf{N}$ & 0.15886 & 0.02077 & $* * *$ \\
$\boldsymbol{\delta}^{\mathbf{1 8}} \mathbf{O}$ & 0.04375 & 0.02570 & $\mathrm{~ns}$ \\
\hline
\end{tabular}

